\title{
INTRODUCING ORGANIZATIONAL CHARACTERISTICS IN LEARNING ENVIRONMENTS
}

\author{
Timo Lainema \\ Turku School of Economics and Business Administration
}

\begin{abstract}
We introduce some present day environmental characteristics affecting modern business organizations. We then argue why these characteristics should be taken into account when designing business-learning environments. The main message of the paper is that we need better learning environments that authentically describe the present day business environment, for example the process nature of business operations and the time aspect of decisionmaking.
\end{abstract}

Key words: Games, Teaching Methods, Organizations.

\section{INTRODUCTION}

The terms 'knowledge work' and 'knowledge worker' are only 40 years old. Today everyone uses these terms, but understanding their implications for managing people and making them productive is still not complete. Another relevant factor is environmental dynamism. Environmental dynamism is the product of several forces operating at one time. These include an increase in the size and number of organizations within an industry, and an increase in the rate of technological change and its diffusion throughout that industry (Li and Simerly, 2002).

During the 1980's the planning loops in the product development and process times in the factory were shortened. New organizational structures enabled fast responses rather than low costs and bureaucratic control. Companies concentrated on reducing if not eliminating delays and using 
their response advantages to attract the most profitable customers (Stalk, 1988). Probably the most significant single factor behind this development has been the use of computers.

Zuboff (1988) argues that new information and control systems have created an integration of production processes. This integration has created jobs that are intrinsically more responsible. The message underlying this new job structure is that being exposed to data implies that a person sees, comprehends, and is appropriately responsive. If organizations are to use information effectively, they must assign each decision to the person best able to make it. Often this will be a worker on an operational level, not a manager. Zuboff argues that this is the primary reason why work force needs a more general education.

This means a shift of emphasis inside the firms: facilitating cooperation among people takes precedence over enforcing compliance, and initiative becomes more valued than obedience. Organizations should make sure that everyone in the company knows how their individual contribution links to the company's overall aspiration (Hamel and Prahalad, 1994).

Zeleny (1989) describes the changes suggested by Zuboff and the other authors. The central or strategic knowledge is supplied to the individuals as an additional knowledge, needed by them in order to coordinate their own plans and action. Adaptation and responsiveness, ultimate decisions must be left to the people who are familiar with particular and local circumstances. Proper use of the locally operational knowledge increases organizational flexibility and its responsiveness to ever-increasing environmental dynamism. In a knowledge-oriented society, planning must be a process of continuous broadening of requisite organizational ability to cope with the ever-wider ranges of relevant internal and external fluctuations. Achieving flexibility demands increase in employee responsibility taking, self-control, and decision-making in ever-wider areas (Zeleny, 1989).

In this paper we will take a closer look at three different organizational environmental characteristics and how they have changed. Based on these changes we synthesize some suggestions that can be used to create authentic business learning environments.

\section{DECISION-MAKING}

There are also changes that affect the whole decision-making procedure. Karin and Preiss (2002) note that business processes have various interactions, which have changed as the business world has moved from static to dynamic environments. Interactions have become more bi- 
directional (compared to mono-directional) and they extend over a longer period of time and often deal with external situations.

Figure 1 (Karin and Preiss, 2002) illustrates the change that has taken place in organizational decision-making. The diagram on the left shows an iterative managerial process. It includes intake of information, analysis, decision and action. This creates a decision loop where information is transmitted once in a decision period, instructions are given and for the remainder of the period the actions taken do not change. The diagram on the right shows the same decision loop as a continuous dynamic process, where information is continuously gathered, decisions continuously reviewed, and the ensuing courses of action change continuously - as in many present day industries.
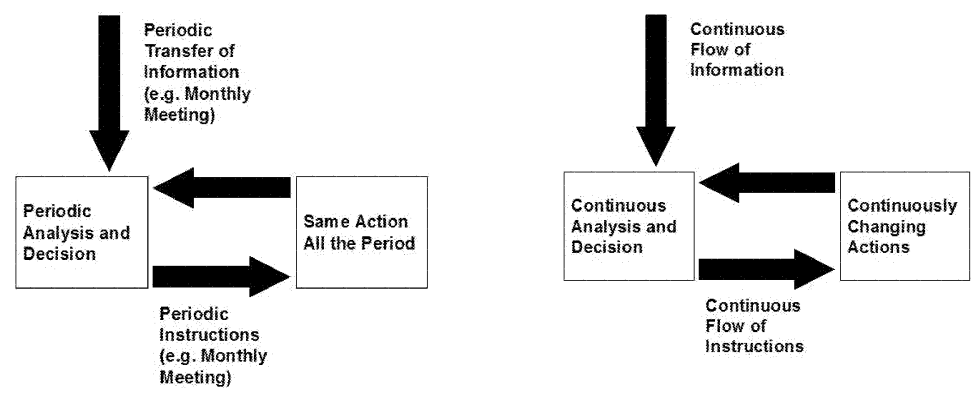

Figure 1. Development in organizational decision-making processes. (Karin \& Preiss, 2002).

We could not verbalize the change in the environment better than Karin and Preiss (2002, p. 65) do:

When (the left diagram of Figure 1) applies to a business situation, the business model is piecewise static. Static because over one decision period the operational plan does not change, piecewise because at the end of a decision period the plan changes suddenly. When [the right diagram of figure 1] applies, the business model is dynamic - for example, suppliers to supermarkets that are required to replenish stock at least twice a day, according to sales data. Such a supplier continuously monitors the sales at all branches of the client supermarket...

The variables in this example, such as quantities to be stocked, are both continuous and dynamic. Continuous, because the values take continuous values, and dynamic, because the values of the variables change with time. In the past, the scenario above could have been expressed by a discrete and static variable. Imagine that the supplier takes orders once a month to supply 
goods to a customer order in only four lot sizes: small, medium, large and extra large. The variable describing the quantity to be supplied is then a discrete variable, having only four possible values. It also is static, since once specified it remains unchanged for a month.

\section{ORGANIZATIONAL STRUCTURES}

Businesses today often operate in competitive environments that are increasingly turbulent and unpredictable (Eisenhardt and Brown, 1999). The turbulence in the business environment and the technological change put pressure on organizations to be sure they can effectively meet the fundamental changes that are occurring (Scott Morton, 1991). External forces associated with environmental turbulence (social, political, technical and economic) and the timing of organizations' responses under such conditions have become crucial to firm survival (Scott Morton, 1991). There is no reason why organizations would necessarily continue in their present form. The environment may be so uncertain that no amount of analysis will allow us to predict the future (Scott Morton, 1991).

While bureaucratic organizations once dominated many aspects of society, most of them are being reshaped along with the challenges around them. This sometimes led to significant transformations (Morgan, 1989). This restructuring has taken place over the past decade, e.g. business units have increasingly taken the role of strategy formulation away from headquarters (Whitney, 1996). As a frame of reference we use a continuum describing the relationship organizations have to their environment. When environmental change becomes the order of the day, open and flexible styles of organization and management are required (Morgan, 1997). Table 1 illustrates extreme patterns of organization and management in organizations experiencing different rates of environmental change.

There are many aspects to be considered from the point of view of training and education in Table 1. Two most important for our field of interest are business processes and time (which have a linkage between each other; time is always embedded as one central factor in processes). 
Table 1: Patterns of organization and management in organizations experiencing different rates of environmental change (after Morgan, 1997).

\begin{tabular}{|l|ll|}
\hline $\begin{array}{l}\text { Attitude } \\
\text { towards } \\
\text { the } \\
\text { environ- } \\
\text { ment }\end{array}$ & $\begin{array}{l}\text { More or less ignorant about the role of } \\
\text { the environment: a closed system that } \\
\text { can be designed as clearly defined } \\
\text { structures of parts. Goals predetermined, } \\
\text { not designed for innovation => Great } \\
\text { difficulty in adapting to changing } \\
\text { circumstances. May lead to: "Wrong } \\
\text { thing well" or "Right thing too late". }\end{array}$ & $\begin{array}{l}\text { Open systems best understood } \\
\text { as ongoing processes rather } \\
\text { than as a collection of parts. } \\
\text { Attention devoted to } \\
\text { understanding the business } \\
\text { environment defined by the } \\
\text { interactions with customers, } \\
\text { competitors, suppliers, etc. }\end{array}$ \\
\hline & MECHANISTIC & ORGANIC \\
\hline & $\begin{array}{l}\text { Mechanistic View; Organizations as } \\
\text { Machines; Taylorian view }\end{array}$ & $\begin{array}{l}\text { Socio-technical view; } \\
\text { Organizations as Open Systems }\end{array}$ \\
\hline
\end{tabular}

For example, when arguing the need to understand business processes we refer to Hammer (1996) who states:

'In short, our problems lie not in the performance of individual tasks and activities, the units of work, but in the processes, how the units fit together into a whole.'

Dutta and Manzoni (1999) argue that the process view emphasizes how an organization actually does what it is required to do across departments and functions. The focus is on trying to communicate how an organization works together to create value for its customers, as opposed to how it is structured. This might imply the need for training which offers employees holistic understanding about the causal interdependencies of organizational processes.

\section{TIME AND DECISION-MAKING}

Traditionally, the goal of management science has been to control uncertainty. But many scholars today admit that it is impossible to have total control over uncertainty. For example, Angell (1997) states that the only logical approach to management is to initiate plans, but to be flexible enough to react quickly to whatever risks or opportunities appear, and to maintain the initiative. A key element here is time, or the progress of time and the ability to live with it. There has been a clear understanding that time is closely related to organizational productivity and that time can be viewed as a resource to be managed. Time is considered one of scarce resources, one to be measured and manipulated in the interest of organizational efficiency and 
effectiveness. One of the most difficult problems in organizational management is to bring objects to the right place at the right time. Bluedorn and Denhardt (1988) quote Moore (p. 8):

Thus one element of temporal ordering is synchronization. Other activities require that actions follow one another in a prescribed order; thus sequence is a part of temporal order. For still other activities, the frequency of events during a time period is critical; thus rate also is one of the ways that time impinges on social behaviour.

Bluedorn and Denhardt (1988, p. 304) argue: "The problem of rate, sequence and synchronization are central to the understanding of time as an organizational resource". Today many groups in organizations must adapt their pacing of task behaviours quickly to changes in time resources. Barkema et al. (2002) found out that besides the speed of organizational processes and activities, also the pace of activities is an important factor. Different organizational processes require different paces and the management challenge is to discover and manage the optimal temporal progression of various processes. Also, time is not evenly distributed. For example, project work groups steadily increase attention to time as deadlines near (Gersick, 1989). Thus, organizations should increasingly pay attention to (a) causal interdependencies of organizational processes and (b) the time dimension of organizational functioning. This means that employees in organizations need to be more aware of the nature of these phenomena.

\section{SYNTHESIS}

The requirements discussed in this paper create a basis of demands that should be taken into account when designing learning environments. Here we conclude these requirements.

- The 'Holistic View' proposition goes as follows: If workers are to become adept at making informed decisions, they need to know the outcomes of their decisions; the cause-effect relationships of their decisions and outcomes. Specialism is not enough anymore, but initiative and a range of abilities should be possessed. Understanding how individual contribution links into the overall goals and ability to deal with novel situations demands from the learning tools/methods/contents above all the ability to deliver a holistic view of organizational and environmental functioning.

- The 'Process and Time Dimensions of Organizations' proposition goes as follows. The participants should be introduced to business processes that evolve as time proceeds. The decision-making starts from the operational 
level. The dynamics between different organizational tasks and functions should be explicit (in the form of processes).

If we accept a view that learning is a kind of research process where the learner strives to gain understanding about the functioning of the phenomenon to be learned ( $=$ to be understood) then the goals of carrying out organizational research are in line with the goals of learning about organizations. Thus, the attributes of the approach of synthesis from Miller and Mintzberg (1983) support our aim of providing holistic process-oriented learning experiences. In the following, we discuss some attributes that Miller and Mintzberg (pp. 62-63) give for an approach that favours a synthesis of internally consistent processes, together with our view of how we have used these attributes in planning learning environments:

- A large number of attributes - ideally of state, process, and situation - are studied simultaneously in order to yield a detailed, holistic, integrated image of reality.

- Causation is viewed in the broadest possible terms. The holistic view of business operations representing networks of causation, not just unidirectional causation between pairs of variables or even multiple forms of causation. A system in which each attribute can influence all of the others by being an indispensable part of an integrated whole.

- Time and process are taken into account wherever possible.

We have applied these principles when constructing a continuously processed process oriented business game. Table 2 rounds up the differences in the characteristics of batch and continuous processing in the case of business gaming.

Table 2: Differences in characteristics between batch-processing and continuous processing.

\begin{tabular}{|l|l|}
\hline Batch-processing & Continuous processing \\
\hline $\begin{array}{l}\text { More a mechanistic view: closed system } \\
\text { that can be designed as clearly defined } \\
\text { structures of parts. }\end{array}$ & $\begin{array}{l}\text { Closer to an open system view: best } \\
\text { understood as ongoing processes rather than } \\
\text { as collection of parts. }\end{array}$ \\
\hline $\begin{array}{l}\text { Centralized decision-making on the } \\
\text { highest level of the business organization. }\end{array}$ & $\begin{array}{l}\text { Decentralized decision-making also on the } \\
\text { lower decision-making levels close to the } \\
\text { actual action. }\end{array}$ \\
\hline $\begin{array}{l}\text { Discrete; stagnant momentary views on } \\
\text { financial and materials situation. }\end{array}$ & $\begin{array}{l}\text { Continuous; the view is continuously } \\
\text { evolving representing the process nature of } \\
\text { business operations, on a transaction } \\
\text { specific level. }\end{array}$ \\
\hline Hierarchy, top-down view. & Process, bottom-up. \\
\hline
\end{tabular}




\section{CONCLUSIONS}

Our conclusion about the above discussion is that if workers are to become adept at making informed decisions, they need to know the outcomes of their decisions. As educators we need to be able to deliver a holistic view of organizational and environmental functioning. We acknowledge the need for providing learning tools, which represent realistic and complex models of reality, are authentic, facilitate continuous problem solving and meaningful learning, and embed learning in social experience. The propositions explicated here shape our conceptual model of how realism should be acquired and embedded in business learning tools.

\section{REFERENCES}

Angell, I. O. (1997).Welcome to the 'Brave New World'. In Stowell and Mingers (Eds.) Information Systems: An Emerging Discipline? (pp. 363-383). New York: Mc Graw-Hill.

Barkema, H. G., Baum, J. A. C., and Mannix, E. A. (2002). Management Challenges in a New Time. Academy of Management Journal, 45 (5), 916-930.

Bluedorn, A. C., and Denhardt, R. B. (1988). Time and Organizations. Journal of Management, 14, 2, 299-320.

Dutta, S,. \& Manzoni, J. (1999). Process Re-engineering, Organizational Change and Performance Improvement. London: McGraw-Hill.

Eisenhardt, K., \& Brown, S. (1999). Patching. Harvard Business Review, 77(3), 72-82.

Gersick, C. J. G. (1989). Marking Time: Predictable Transitions in Task Groups. Academy of Management Journal, 32(2), 274-309.

Hamel, G. \& Prahalad, C. (1994). Competing for the Future. Boston: Harvard Business School Press.

Hammer, M. (1996). Beyond Reengineering. Harper Business.

Karin. I. \& Preiss, K. (2002). Strategic Marketing Models for a Dynamic Competitive Environment. Journal of General Management, 27(4) 63-78.

Li, M. \& Simerly, R. (2002). Environmental Dynamism, Capital Structure and Innovation. The International Journal of Organizational Analysis, 10(2), 156-171.

Miller, D., \& Mintzberg, H. (1983). The Case for Configuration. In G. Morgan (Ed.) Beyond Method. Strategies for Social Research. (pp. 57-73). California: Sage Publications.

Morgan, G. (1989). Creating Organization Theory: A Resource book. California: Sage Publications.

Morgan, G. (1997). Images of Organization. California: Sage Publications.

Scott Morton, M. S. (1991). The Corporation of the 1990's - Information Technology and Organizational Transformation. Oxford University Press.

Stalk, G. (1988). Time - The Nest Source of Competitive Advantage. Harvard Business Review, 66(4), 41-51.

Whitney, J. O. (1996). Strategic Renewal for Business Units. Harvard Business Review, 74(4), 84-98.

Zeleny, M. (1989). Knowledge as a New Form of Capital. Human Systems Management. 8, 77-90. 
Zuboff, S. (1988). In the Age of the Smart Machine. The Future of Work and Power. Oxford: Heinemann.

\section{BIOGRAPHY}

Timo Lainema has research interests in developing interactive and authentic business games for business education purposes. This research is multidisciplinary and includes such research topics as the impact of time in decision-making, business processes, structured versus unstructured decision-making, experiential learning, organizational learning and constructivist learning principles. Timo's email address: timo.lainema@tukkk.fi. 